\title{
SEX STEROID HORMONES AND VOLUNTARY EXERCISE IN RATS
}

\author{
S. A. ASDELL, H. DOORNENBAL* and G. A. SPERLING \\ Animal Husbandry Department, Cornell University, Ithaca, New York, U.S.A.
}

(Received 12th September 1961)

\begin{abstract}
Summary. Oestrogen pellets implanted in castrated or spayed rats cause both the males and females to take a considerable amount of voluntary exercise. Testosterone pellets cause implanted spayed females to take considerable exercise but their effect on the castrated male is much less. If the male has previously been under the influence of an oestrogen pellet, the amount of activity that results when a testosterone pellet is implanted is increased. The suggestion is made that once the responsible brain centre has been exposed to oestrogen it becomes sensitive to the action of testosterone.
\end{abstract}

\section{INTRODUGTION}

During the course of an experiment in which oestrogen and androgen pellets were implanted into rats, it was noticed that those with oestrogen implants were very restless and had the habit of chewing their food pellets and dropping the fragments through the wire floors of the cages. This observation led to a study of the relationship of sex steroid hormones and voluntary exercise in rats. That such a relationship exists has long been known. Wang (1923) observed that, when female rats were placed in activity cages and a daily record of their voluntary activity made, peaks occurred every 4 or 5 days. The ovariectomized female was much less active and her record showed no such peaks. As the peaks occurred on the days that the rats were in heat, it was concluded that the increased activity was part of the general condition of oestrus, a conclusion that was confirmed by Slonaker $(1924,1925)$. This worker added the fact that activity was depressed during the latter part of gestation and in pseudopregnancy. $\mathrm{He}$ also recorded that males showed no regular peaks of activity. Richter (1933) showed that gonadectomy considerably reduced the spontaneous running activity of both sexes and abolished any rhythmic peaks.

It is clear from this work that the amount of spontaneous activity in both sexes is related to the presence of the gonads and it may be presumed that oestrogens and androgens are responsible for the higher level in normal as compared with gonadectomized rats. Hemmingsen \& Krarup (1937) found that a synthetic oestrogen, $9: 10$ dihydroxy-9:10-di-n-propyl-9:10 dihydro-1 $: 2: 5: 6$-dibenzanthracene, injected into four spayed rats increased the activity of each of them. The daily activity range of the rats was,

* Present address : Dominion Experimental Farm, Lacombe, Alberta, Canada. 
before injection, between 497 and 1230 revolutions of the drum. After the injections, the means for these rats ranged from 3620 to 6400 revolutions. With injected theelin and theelol, these workers obtained weak responses in two of their rats. Richter \& Hartman (1934) injected oestrogen in the form of amniotin at the rate of 5 r.u. daily and obtained a marked increase in the spontaneous activity of spayed rats. Young \& Fish (1945) observed a very marked increase in spontaneous activity in spayed rats implanted with 2.8 to $3.7 \mathrm{mg}$ pellets of oestrone. Injected oestradiol benzoate was less effective at the rate of 10 r.u. daily. Progesterone injections did not increase the amount of activity when it was injected during these treatments. The conclusion was drawn that these two hormones do not act synergistically in promoting spontaneous activity.

In the castrated male rat, Richter \& Hartman (1934) observed that injected oestrogen (amniotin) increased the amount of spontaneous activity, but that it was not raised to the level characteristic of the normal male. Hoskins \& Bevin (1940) selected eleven senile rats that showed very little spontaneous activity, of the order of 250 revolutions of the drum per week, and gave them oestriol glucuronide mixed with their food. Most of the rats responded by increasing their voluntary activity. This rose, in one case, to as much as 4000 revolutions a week. The evidence indicates that oestrogens increase the activity of males as well as of females.

Although there is general agreement that castration reduces the amount of voluntary exercise taken by the male rat, it has not been demonstrated that the level of androgen influences the amount of activity in this sex. Heller (1932) pointed out the large differences between rats in regard to the amount of exercise they took, but he was unable to correlate these differences with differences in size and activity of the accessory sex organs. Furthermore, he was unable to obtain consistent increases in activity when he injected seven bird units of an androgenic preparation into normal or castrate rats. He concluded that androgens were 'at least not the sole factor' in spontaneous activity of male rats.

It is evident from this literature review that not much is known on the subject and that it merits further investigation.

\section{EXPERIMENTAL}

The rats used in this work belong to the Cornell strain which is derived from the Osborne and Mendel strain. They are a small albino rat and the colony has been a closed one for many years. No attempt at inbreeding or linebreeding has been made during the past 30 years. The rats are fed ad lib. on a commercial rat pellet. Young rats were used and, in those that were spayed or castrated, the operation was performed at from 40 to 65 days of age. Activity was measured in an eight-cage battery with revolving drums equipped with revolution recorders. Readings were made daily at $10 \mathrm{a} . \mathrm{m}$. and 7-day averages were used as the basis for comparison. About 1584 revolutions of the drum represent 1 mile of running.

Sex steroid hormone administration was in the form of small rods that were 
inserted beneath the skin of the flank with a sharpened tube and a plunger. They were inserted as far as possible from the puncture site so that there was little chance of their working out or being extracted by the rat. Except in the last trial, the pellets weighed about 54 to $55 \mathrm{mg}$ and consisted of $1.05 \mathrm{mg}$ of oestradiol benzoate or testosterone propionate together with $19.45 \mathrm{mg}$ of cholesterol. The remainder was dibasic calcium phosphate with a little cornstarch and magnesium stearate. In the last trial, some pellets containing $10 \mathrm{mg}$ of testosterone propionate were used.

\section{FIRST TRIAL}

This was an exploratory trial in which a normal male and female were tested. Also a castrate male and an ovariectomized female were implanted with an androgen pellet and similar rats were implanted with an oestrogen pellet. The results were as follows:

(1) The normal female showed typical 5-day cycles. Her 7-day average was, at first, about 2000 revolutions daily, but, after 10 weeks in the activity cage, it dropped to below 1000 and continued at that level.

(2) The ovariectomized female performed at first at a rate of 3000 revolutions a day but after 13 weeks she dropped to a little below 2000 revolutions daily.

(3) The spayed female with an oestrogen pellet rose from an initial level of 500 to 10,000 revolutions daily. At the end of 6 weeks, she developed an abscess of the jaw and was discarded. Another spayed rat was implanted with an oestrogen pellet and her activity rose from 500 revolutions a day to a peak of 13,000 at 8 weeks after the implant was made. Her activity level then began to fall and an additional implant made after a week had elapsed did not arrest the fall except, perhaps, temporarily, 3 weeks later.

(4) The spayed female with the testosterone pellet made a remarkable record. She rose from an initial level (after spaying) of 250 revolutions a day to a peak of 15,500 daily. A second implant at this point, 8 weeks after the first, was followed by a slight decline for 3 weeks and then a new peak of activity at 19,000 revolutions a day. This was sustained at almost the same level for 3 weeks, when a rapid decline set in. A new implant 8 weeks after the previous one was followed by only a small, temporary rise.

(5) The normal male showed a fluctuating activity level which varied from a weekly average of from 1500 to 2700 revolutions a day.

(6) The castrated male showed a very uniform average of about 300 revolutions a day.

(7) The castrated male with an oestrogen implant gave a peak of 6700 revolutions a day after 4 weeks had elapsed. Activity was declining and at 8 weeks a new pellet was then inserted. Activity rose by the 12th week to 11,000 revolutions a day, after which the decline was rapid. Another implant at 17 weeks brought a new peak of 12,000 revolutions a day reached in 21 weeks. Then the decline was again very rapid.

(8) The castrated male with an androgen pellet showed a rise that brought it level with the normal male at 6 weeks but its activity then gradually declined and further implants at 8 and 17 weeks elicited no response. 
These trials suggested that the androgen was effective only in the female. Further work was planned to verify, if possible, this unexpected, tentative conclusion.

\section{SECOND TRIAL}

This trial was designed to test the activity of testosterone in the castrated male and spayed female. Four of each were placed in activity cages and their exercise measured for 2 weeks. They were then implanted with one pellet of androgen each. Their activity was recorded for a further 5 weeks. The results are given in Table 1. All four of the females responded to the implant

TABLE 1

EFFECT OF TESTOSTERONE PROPIONATE IMPLANTS UPON THE AVERAGE DAILY ACTIVITY OF GONADEGTOMIZED MALE AND FEMALE RATS

\begin{tabular}{c|c|c|c|c|c|c|c|c}
\hline \multirow{2}{*}{ Period by weeks } & \multicolumn{5}{|c|}{ Males } & \multicolumn{5}{c}{ Females } \\
\cline { 2 - 9 } & 1 & 2 & 3 & 4 & 5 & 6 & 7 & 8 \\
\hline $\begin{array}{c}\text { Pre-implant } \\
\text { week 2 } \\
1\end{array}$ & 4,131 & 5,613 & 9,105 & 4,383 & 7,038 & 5,873 & 8,308 & 8,008 \\
\hline & 4,033 & 3,984 & 7,768 & 4,972 & 5,943 & 4,550 & 5,889 & 7,103 \\
\hline Post-implant & & & & & & & & \\
week 1 & 5,206 & 4,084 & 10,987 & 8,831 & 13,017 & 10,236 & 14,408 & 18,522 \\
2 & 5,134 & 3,623 & 8,196 & 8,393 & 12,090 & 6,381 & 11,989 & 14,247 \\
3 & 4,422 & 2,628 & 5,269 & 4,262 & 8,436 & 5,169 & 9,083 & 10,977 \\
4 & 3,473 & 1,948 & 4,599 & 3,779 & 6,202 & 2,873 & 4,005 & 4,959 \\
5 & 2,576 & 1,852 & 4,488 & 1,878 & 4,536 & 2,789 & 3,379 & 3,475 \\
\hline
\end{tabular}

The data represent the number of activity-drum revolutions recorded per day.

by taking more exercise, but the stimulation did not last for more than 3 weeks. The effect upon the males was doubtful. There was one good increase, one doubtful one and two without response. But the one response that could be regarded as positive was much less than those of the females, which were unequivocal.

THIRD TRIAL

This trial was made to determine whether the oestrogen effect on castrated males was definitely to increase activity and to compare it with the effect upon spayed females. Four rats of each kind were placed in the activity battery and their amount of exercise recorded for 2 weeks. Each was then implanted with one oestrogen pellet and the activity measured for an additional 8 weeks. The results are given in Table 2 . In all the rats, the increase in activity was very marked. There was no doubt that oestrogen in the dose given stimulated the castrated males to activity.

FOURTH TRIAL

This trial was intended to decide whether the comparative lack of response to testosterone by the castrate male was due to insufficient dosage. Four castrate 
males that had not previously received oestrogens were placed in the battery after one had received a single 1-mg pellet of testosterone propionate; one, a single 10-mg pellet; and one, two $10-\mathrm{mg}$ pellets. The fourth rat received no implant. Four more castrate rats were treated similarly. Each of these had previously been implanted with oestrogen pellets but the effects had subsided when the rats were placed on the fourth trial. The results are given in Table 3.

TABLE 2

EFFEGT OF OESTRADIOL BENZOATE IMPLANTS UPON THE AVERAGE DAILY AGTIVITY OF GONADECTOMIZED MALE AND FEMALE RATS

\begin{tabular}{|c|c|c|c|c|c|c|c|c|}
\hline \multirow{2}{*}{ Period by weeks } & \multicolumn{4}{|c|}{ Males } & \multicolumn{4}{|c|}{ Females } \\
\hline & 9 & 10 & 11 & 12 & 13 & 14 & 15 & 16 \\
\hline $\begin{array}{c}\text { Pre-implant } \\
\text { week } 2 \\
1\end{array}$ & $\begin{array}{l}4,427 \\
1,498\end{array}$ & $\begin{array}{l}8,249 \\
7,441\end{array}$ & $\begin{array}{r}6,853 \\
11,187\end{array}$ & $\begin{array}{l}4,793 \\
6,767\end{array}$ & $\begin{array}{l}6,455 \\
8,461\end{array}$ & $\begin{array}{r}6,355 \\
11,429\end{array}$ & $\begin{array}{l}5,669 \\
9,959\end{array}$ & $\begin{array}{l}2,339 \\
4,835\end{array}$ \\
\hline $\begin{array}{c}\text { Post-implant } \\
\text { week } 1 \\
2 \\
3 \\
4 \\
5 \\
6 \\
7 \\
8\end{array}$ & $\begin{array}{r}5,795 \\
7,112 \\
11,756 \\
17,815 \\
16,645 \\
10,792 \\
5,748 \\
1,871\end{array}$ & $\begin{array}{r}14,566 \\
11,378 \\
14,962 \\
13,037 \\
15,955 \\
8,493 \\
2,250 \\
2,983\end{array}$ & $\begin{array}{r}16,358 \\
20,547 \\
19,472 \\
20,283 \\
18,290 \\
9,142 \\
2,830 \\
2,012\end{array}$ & $\begin{array}{r}16,281 \\
23,123 \\
23,617 \\
23,697 \\
22,346 \\
11,202 \\
5,520 \\
3,086\end{array}$ & $\begin{array}{r}15,436 \\
22,077 \\
19,219 \\
15,469 \\
16,337 \\
12,932 \\
15,043 \\
9,629\end{array}$ & $\begin{array}{l}18,077 \\
22,006 \\
19,184 \\
18,563 \\
21,680 \\
22,058 \\
21,112 \\
18,749\end{array}$ & $\begin{array}{l}13,713 \\
19,985 \\
21,678 \\
18,575 \\
17,681 \\
19,953 \\
13,930 \\
12,089\end{array}$ & $\begin{array}{r}10,419 \\
10,189 \\
5,774 \\
8,371 \\
4,487 \\
5,541 \\
1,439 \\
363\end{array}$ \\
\hline
\end{tabular}

The data represent the number of activity-drum revolutions recorded per day.

TABLE 3

EFFECT OF ANDROGEN DOSAGE AND PREVIOUS TREATMENTS WITH OESTROGEN UPON THE AVERAGE DAILY ACTIVITY OF CASTRATED MALE RATS

\begin{tabular}{|c|c|c|c|c|c|c|c|c|}
\hline \multirow[b]{2}{*}{$\begin{array}{c}\text { All post-implant } \\
\text { weeks }\end{array}$} & \multicolumn{4}{|c|}{ Not previously treated with oestrogen } & \multicolumn{4}{|c|}{ Previously treated with oestrogen } \\
\hline & $2 \stackrel{17}{\times 10}$ & $1 \stackrel{18}{\times 10}=$ & $1 \underset{\mathrm{mg}}{19}$ & $\begin{array}{c}20 \\
\text { no } \\
\text { implant }\end{array}$ & $2 \underset{\mathrm{mg}}{\mathrm{l}} \stackrel{10}{\mathrm{~m}}$ & $1 \stackrel{9}{\times 10}$ & $1 \underset{\mathrm{mg}}{11}$ & $\begin{array}{c}12 \\
\text { no } \\
\text { implant }\end{array}$ \\
\hline $\begin{array}{l}1 \\
2 \\
3 \\
4\end{array}$ & $\begin{array}{r}900 \\
2,365 \\
2,982 \\
1,217\end{array}$ & $\begin{array}{r}709 \\
1,201 \\
1,108 \\
1,467\end{array}$ & $\begin{array}{l}1,571 \\
3,110 \\
1,464 \\
1,046\end{array}$ & $\begin{array}{r}549 \\
1,704 \\
1,873 \\
931\end{array}$ & $\begin{array}{r}12,216 \\
14,108 \\
13,628 \\
9,141\end{array}$ & $\begin{array}{r}6,378 \\
10,328 \\
8,058 \\
1,917\end{array}$ & $\begin{array}{l}7,545 \\
9,401 \\
2,728 \\
1,798\end{array}$ & $\begin{array}{l}9,025 \\
7,802 \\
3,164 \\
2,364\end{array}$ \\
\hline
\end{tabular}

The data represent the number of activity-drum revolutions recorded per day.

In the rats that had not previously been treated with oestrogen, the average daily activity showed a small rise, but there was no difference between the implants and the control. In no case did the level rise above 3000 revolutions. The rats that had been previously implanted with oestrogen behaved in a very different manner. During the 1st week, the rat with $20 \mathrm{mg}$ of testosterone propionate rose to 12,400 revolutions and it increased that level in the 2 following weeks. The rat with $10 \mathrm{mg}$ rose to 7600 and it, too, rose above that 
level in the 2 following weeks. The l-mg rat rose to 7000 and then to 9300 , but in the 3rd week its decline was precipitous. However, the control evidently was stimulated by the handling necessary in setting up the new trial for it rose to 9000 in the 1st week. It then declined rapidly in the 2nd and 3rd weeks.

From this trial it may be concluded that the dose levels had little effect upon the activity of the males, but that previous treatment with oestrogen sensitized the male to the androgen so that considerable activity resulted when a testosterone implant was made.

\section{DISCUSSION}

It is not possible without further work to decide where the sex steroid hormones, oestradiol and testosterone, act to cause the rat to indulge in a high degree of spontaneous activity. It is evident that, wherever this brain centre may be, it is sensitive to oestrogens and that once it has been sensitized, it responds to testosterone as readily, or even more readily than it does to oestrogens. Testosterone succeeded in stimulating our females because oestrogens had already been active by the time when the ovariectomies had been performed. In the males, the oestrogen had not been present so that they did not respond, or only responded to a small degree to testosterone. Our work poses a number of questions. When in early life, does the postulated centre first become sensitive to testosterone, i.e., when has sufficient oestrogen been secreted to make it sensitive? How much oestrogen is needed to sensitize? What is the nature of this sensitization? Does it depend upon the development of enzymic mechanisms that cause testosterone to be converted to oestrogen? Does the normal male ever become sensitive to testosterone? How long does the sensitization last?

An alternative explanation is to assume that there is an inherent difference in the male and female brain and that oestrogen overcomes that difference. This does not seem to us to be a reasonable hypothesis and unless there is good reason from other work, unknown to us, to suggest such a possibility, we prefer not to entertain it.

\section{ACKNOWLEDGMENTS}

We are indebted to Dr R. H. Silber, Research Laboratory, Merck, Sharp and Dohme, for the supply of oestradiol and testosterone pellets. Our thanks are due to Mrs $\mathbf{R}$. Seither for the efficient way in which she has ministered to the rats.

This investigation was supported by research grant A3299-Endo, made by the United States Public Health Service, Department of Health, Education and Welfare.

\section{REFERENCES}

Heller, R. E. (1932) Spontaneous activity in male rats in relation to testis hormone. Endocrinology, 16,626 .

Hemmingsen, A. M. \& KraruP, N. B. (1937) The production of mating instincts in the rat with chemically well-defined oestrogenic compounds. Kgl. Danske Videnskab. Selskab, Biol. Medd. 13, No. 8. 
Hoskins, R. G. \& Bevin, S. (1940) The effect of estriol glucoronide on the spontaneous activity of senile male rats. Endocrinology, 26, 829.

Richter, G. P. (1933). The effect of early gonadectomy on the gross body activity of rats. Endocrinology, 17,445 .

Richter, C. P. \& Hartman, C. G. (1934) The effect of injection of amniotin on the spontaneous activity of gonadectomized rats. Amer. F. Physiol. 108, 136.

SLonaker, J. R. (1924) The effect of pubescence, oestruation and menopause on the voluntary activity in the albino rat. Amer. 7. Physiol. 68, 294.

SLONAKER, J. R. (1925) The effect of copulation, pregnancy, pseudopregnancy and lactation on the voluntary activity and food consumption of the albino rat. Amer. 7. Physiol. 71, 362.

WANG, G. H. (1923) The relation between spontaneous activity and oestrous cycle in the white rat. Comp. Psychol. Monog., vol. 2, No. 6. Williams \& Wilkins Co., Baltimore.

Young, W. C. \& Fish, W. R. (1945) The ovarian hormones and spontaneous running activity in the female rat. Endocrinology, 36, 181. 